\author{
Mariusz M. Leś \\ Wydział Filologiczny \\ Uniwersytet w Białymstoku \\ e-mail: mariusz.m.les@gmail.com
}

\title{
Nostalgia retrofuturystów
}

\author{
About the future I only can reminisce. \\ For what I've had is what I'll never get. \\ And although this may sound strange \\ My future and my past are presently disarranged. \\ And I'm surfing on a wave of nostalgia \\ For an age yet to come...
}

Buzzcocks, Nostalgia for an Age Yet to Come

Niniejszy artykuł stanowi próbę zarysowania tego fragmentu badań nad poetyką fantastyki naukowej, który w centrum zainteresowania mógłby umieścić emocjonalny aspekt odbioru towarzyszący odpowiednim estetyczno-poznawczym schematom budowy dzieła charakterystycznym dla tej dziedziny literackiej. Wybór padł na bodaj najbardziej wyrazisty zespół schematów, umieszczany często w definicji - na konstrukcję czasu w science fiction.

Kiedy Samuel R. Delany próbował - jak wielu przed nim i wielu po nim - określić swoistość science fiction bez odwoływania się do potocznych, powierzchownych opinii, za kryterium obrał relację między czasem fikcyjnym a rzeczywistym wraz ze stopniem aktualizacji wydarzeń. Reportaż określony zostaje przez formułę "to się wydarzyło", realizm - "to się mogło wydarzyć", fantasy - "to się nie mogło zdarzyć". Nic prostszego mogłoby się wydawać - science fiction będzie zapewne ograniczone przez formułę "to się będzie mogło zdarzyć". Owszem, Delany przywołuje także ją, ale fikcjonalna światotwórcza energia znacznie poszerza granice możliwości. Otóż science fiction może mieścić się również w formułach „to się nie zdarzy" (w pośrednim 
wariancie science fantasy), "to się jeszcze nie wydarzyło" (ostrzegawcza dystopia) oraz "to się nie zdarzyło" ${ }^{1}$. Fantastyka naukowa jest bowiem w stanie motywować historię i teraźniejszość alternatywną, przyszłość alternatywną oraz potencjalną teraźniejszość (w wariancie zwanym political fiction). Delany nazywa te cechy światów fikcyjnych ich "podłączliwością” (subjunctivity) ${ }^{2}$. Pod co „podłącza się" science fiction? Pod „naszą" rzeczywistość, świat „aktualny" - w terminologii teorii światów możliwych.

Można by oczywiście (właściwie - należałoby) polemizować z Delanym co do czystości wyróżnionych przez niego kategorii, ale z pewnością wart zauważenia jest fakt, że science fiction istnieje na skrzyżowaniu wielu płaszczyzn oraz kierunków temporalnych, a punkt ciężkości nie jest przesunięty wyłącznie na przyszłość i kierunek teraźniejszość-przyszłość. Przyszłość wcale nie przeważa, wygrywa strategia paramimetyczna, skoncentrowana na „podłączaniu” światów. Science fiction w przeważającej postaci oferuje linię mentalnego powrotu do teraźniejszości, by czytelnik w trakcie lektury i po jej zakończeniu potrafił odnaleźć łącznik między własną teraźniejszością a wykreowaną $\mathrm{w}$ dziele przyszłością lub alternatywnością, może to być ekstrapolacja, może być też alegoria. Punktem wyjścia i dojścia jest w takim przypadku realność, ale różnica, czyli fantastyczność jest nieredukowalnym sposobem generowania znaczeń. Zakłada ona szok poznawczy połączony z potencjalną emocjonalną reakcją odrzucenia, lęku, wyobcowania $\mathrm{w}$ zderzeniu $\mathrm{z}$ innością (nie muszę chyba pisać, że idzie tu o dobrze skonstruowany utwór fantastyczny). Różnie ta reakcja bywała konceptualizowana, do najpopularniejszych z pewnością należy koncepcja Darka Suvina wyobcowania czytelnika - estrangement ${ }^{3}$. Pisano również o konieczności tekstualizacji i fikcjonalizacji własnej rzeczywistości w kontakcie z perswazyjnym światem fikcyjnym ${ }^{4}$.

Jeśli dodać do powyższych ustaleń kolejne czynniki, sytuacja skomplikuje się jeszcze bardziej. Pierwszy z dodatkowych czynników dotyczy niezgodności rzeczywistej sytuacji pragmatycznej z fikcyjną w przypadku większości utworów fantastycznonaukowych, tych futurystycznych. W logice fikcji narracja prowadzona $\mathrm{w}$ czasie przeszłym dotyczy zdarzeń przeszłych jeszcze głębiej zanurzonych $\mathrm{w}$ fikcyjnej przeszłości. Natomiast w nadrzędnym

1 S.R. Delany, About 5,750 Words, w: The Jewel-Hinged Jaw. Notes on the Language of Science Fiction, Middletown 2009, s. 10.

2 Tamże.

3 D. Suvin, Poetyka science fiction, przeł. B. Okólska, w: Spór o SF, red. R. Handke, L. Jęczmyk, B. Okólska, Poznań 1989.

4 G. Jones, Deconstructing the Starships: Science, Fiction, and Reality, Liverpool 1999, s. 5. 
akcie komunikacji literackiej zdarzenia te znajdują się w sferze fikcyjnej (potencjalnej lub alternatywnej) przyszłości. Już na poziomie narracji, akt komunikacji fikcyjnej nie powinien być zatem zrozumiały dla rzeczywistego odbiorcy, a przynajmniej ta niezrozumiałość winna być skalowana w zgodzie z dystansem czasowym dzielącym planowany czas odbioru od czasu zdarzeń fikcyjnych. Futurystyczność czy alternatywność mogą być rozpatrywane jako "fikcja niemożliwa" ${ }^{5}$, ale ta niemożliwość podlega zagospodarowaniu jako energetyczny paradoks. $Z$ drugiej strony zawsze zostawiają one swe ślady na ogólnym przekazie utworów. W przypadku alegorycznego „Zwrotu semantycznego" kreacja fantastyczna służy poruszaniu problemów teraźniejszych lub przeszłych wobec zakładanego aktu komunikacji literackiej. Ale i alegoria przecież zostawia ślady. Nie sposób na przykład omawiać Folwarku zwierzęcego George'a Orwella bez śladu „zezwięrzęcenia” stosunków międzyludzkich, podobnie jak nie sposób nie wspomnieć w przypadku Roku 1984 o globalnym wymiarze totalitaryzmów. Allotopie ${ }^{6}$, czyli utwory radykalnie egzomimetyczne ${ }^{7}$, zakładające pełne "zanurzenie” odbiorcy $\mathrm{w}$ świecie fantastycznym i rezygnację $\mathrm{z}$ odniesień do rzeczywistości, wciąż stanowią rzadkość, wymagającą przy tym odpowiednio radykalnego nastawienia czytelniczego.

Drugi z czynników związany jest z faktem, że proza o orientacji futurystycznej zazwyczaj bardzo szybko podlega przesunięciom w stronę obszarów archiwalnych. Dzieje się tak, gdy data realnego odbioru wykracza poza datę fikcyjnych zdarzeń. Nawet jeśli jesteśmy do końca przekonani, że fantastyka naukowa - jako konwencja literacka - nie ma ambicji profetycznych, to daty (również przybliżone i implikowane) wpływają na możliwość zaistnienia zdarzeń, co ma wpływ przede wszystkim na siłę iluzji, intensywność "wyobcowania" i immersji, a w skrajnych przypadkach czytelniczej niewiedzy - przesuwa w odbiorze fantastykę z kategorii futurystycznej i ekstrapolacyjnej ku historii alternatywnej. Takie zjawisko wydaje się naturalną przypadłością science fiction, ale czasem, szczególnie w przypadku dzieł najsłynniejszych i popularnych autorów, dodaje pewnego uroku, podobnego do tego, który stopom miedzi nadaje patyna. Patyna jest świadectwem autentyczności i historii przedmiotu. Patynowanie jest już następstwem rozpoznania tego uroku. Jeśli utwory Verne'a są świadectwem swego czasu, po części proro-

\footnotetext{
5 Impossible Fiction: Alternativity - Extrapolation - Speculation, red. D. Littlewood, P. Stockwell, Amsterdam-Atlanta 1996.

6 K.M. Maj, Allotopie. Topografia światów fikcjonalnych, Kraków 2015.

7 A. Zgorzelski, SF jako pojęcie historycznoliterackie, w: Spór o SF. Antologia szkiców i esejów o science fiction, red. R. Handke i in., Poznań 1989, s. 145.
} 
cze, po części chybione, to właśnie te ostatnie przepowiednie czynią dzieło Verne'a wielowymiarowym, autentycznym świadectwem, którego wartości nie da się zredukować do pewnego punktu w postępie wiedzy naukowej i technologii, dzisiaj już znacznie bardziej zaawansowanych, usuwających więc swe niedoskonałe warianty $\mathrm{w}$ niepamięć teraźniejszego praktycyzmu. Czasem chęć poddania się temu urokowi prowadzi do odkryć, "powtórnych" odkryć, gdy zmiana czasu odbioru powoduje zmiany perspektywy lektury. Łatwiej dziś wyłowić urok początkowych partii powieści Juliusza Verne'a Z Ziemi na Księżyc (1865), opisujących krótką historię Klubu Artylerzysty i jego posiedzenie, dostrzec motywacje niecodziennej podróży na Księżyc, której pomysł rodzi się $\mathrm{w}$ chaosie albo wręcz $-\mathrm{z}$ chaosu.

Jeśli do przeszłych wyobrażeń o przyszłości sięga się po to właśnie, by rozwinąć ten kompleksowy urok sięgający poza współczesne wyobrażenia o postępie, można mówić o „retrofuturyzmie”. Tym się on różni od „zwykłej" postawy retro, że angażuje zogniskowaną, wyostrzającą postawę antycypacyjną. Wysiłek diagnozowania krzyżuje się z wysiłkiem konstruowania ${ }^{8}$. Retrofuturyzm to zatem świadoma strategia twórcza, która powołuje do fikcyjnego życia alternatywne światy oparte na przeszłych, zamkniętych i wyrazistych, zdezaktualizowanych wyobrażeniach o przyszłości ${ }^{9}$. Utwór retrofuturystyczny musi przy tym przestrzegać reguły wewnętrznej spójności świata, czyli powinien być światem możliwym.

Strategia ta najpełniej realizowana jest w subkonwencji steampunku. Ponieważ steampunk opiera się na wyraźnej, także wizualnej, różnicy między wersjami teraźniejszości, różnicy, która nie tyle dotyka ludzi i ich kreacji, co przede wszystkim technologii otaczającej człowieka, wydaje się szczególnie interesujący dla kontrowersyjnego kierunku w humanistyce zwanego humanistyką cyfrową. Bada ona przede wszystkim charakter relacji między człowiekiem a maszyną ${ }^{10}$. Steampunk zaś przywołuje swoisty determinizm

8 ,[C]ognitively it is still more demanding to imagine the future than to recall the past" [C. Hammond, Time Warped: Unlocking the Mysteries of Time Perception, Harper, New York 2013, s. 230].

9 Retrofuturyzm to "przypomnienie antycypacji” („If futurism is a term that describes our anticipation of what is to come, then retrofuturism describes how we remember these visions") - mówi jedna z najbardziej lakonicznych i zarazem najbardziej trafnych definicji. E. Guffey, K.C. Lemay, w: The Oxford Handbook of Science Fiction, red. R. Latham, Oxford 2014, s. 434.

10 "Retrofuturism and alternate history form a dialogue between academic and public participants of the digital humanities [...]. We analyze history from different cultural and historical positions, most of which never come into existence. But even those abandoned futures impact the layers of human stories, dead organisms, and non-human media constructing the past" [R. Whitson, Steampunk and Nineteenth-Century Digital Humanities: Literary Retrofuturisms, Media Archeologies, Alternate Histories, Routledge: New York-London, s. 15]. 
techniki (wieku XIX - „wieku pary”), w którym przyczynowo-skutkowy łańcuch kluczowych wydarzeń koncentruje się na rozwoju technologii ${ }^{11}$. Oczywiście, steampunk stanowi mieszaninę różnych odwołań i zazwyczaj jest umieszczany w nurcie "postmodernizacji” science fiction i fantasy, co prowadzi do wzmacniania "nieczystych" i nowych kategoryzacji, w rodzaju science fantasy czy urban fantasy, a ostatecznie - do "opatentowania" nowej mieszaniny pod nową nazwą, taką jak np. new weird. Alternatywna technologia staje się w steampunku osią światostwórstwa i motorem fabuły, niemalże fetyszem nowej subkonwencji ${ }^{12}$, choć - trzeba przyznać - bywa traktowana z przymrużeniem oka. W Polsce steampunk nie przeżył takiego rozkwitu, pozostając w cieniu głównonurtowej historii alternatywnej zainteresowanej kluczowymi wydarzeniami politycznymi ${ }^{13}$.

Retrofuturyzm stanowi świadectwo stabilizacji konwencji fantastycznonaukowej jako samodzielnej dziedziny, niezależnej od futurologii. Nie jest to pierwsze takie świadectwo, bowiem już w latach 60. ubiegłego wieku "nowa fala" science fiction przedkładała stylistyczną jakość, narracyjne eksperymenty ponad poprawność naukowo-techniczną. W przypadku retrofuturyzmu przyszłość nie jest już $w$ najmniejszym stopniu podejrzana o „sprawdzalność”, ponieważ stanowi alternatywną wersję teraźniejszości. Dzieła futurologiczne zresztą jeszcze szybciej i bardziej regularnie niźli science fiction przechodzą do kategorii archiwaliów, gdy ważniejsze staje się świadectwo historyczne przyszłościowej wyobraźni i świadomości niż rzeczywisty potencjał profetyczny. Tak stało się chociażby z Summa technologiae Stanisława Lema. W odbiorze na Zachodzie dzieło to znane przez kilkadziesiąt lat nielicznym jako futurologiczne, odbierane jest dziś przede wszystkim jako świadectwo archiwalno-nostalgiczne. $W$ tym przypadku proces ten wzmocniły także okoliczności polityczne i wydawnicze ${ }^{14}$. Różnice między fantastyką a futurologią są oczywiste: fantastyka operuje światami prywat-

11 Zwłaszcza oczywiście w tej formie steampunku, która bliższa jest science fiction, i która powstała przede wszystkim jako transpozycja cyberpunku, czyli np. w powieści Williama Gibsona i Bruce'a Sterlinga The Difference Engine (1990, pol. przekład: Maszyna różnicowa, przeł. P. Cholewa, Warszawa 1997).

12 C.J. Miller, A. Bowdoin Van Riper, Blending Genres, Bending Time: Steampunk on the Western Frontier, „Journal of Popular Film \& Television” 2011, nr 2, s. 85.

13 M. Górecka, Historie alternatywne w konwencji steampunk $i$ cyberpunk - wariacje na temat powstania styczniowego w powieściach Konrada T. Lewandowskiego i Adama Przechrzty, "Acta Humana" 2013, nr 1, s. 38-39. Podobnie pisał Paweł Majka - P. Majka, Przywieźli wegeiel, "Czas Fantastyki" 2014, nr 1.

14 M.M. Leś, Summa technologiae odnaleziona w przekładzie, „Białostockie Studia Literaturoznawcze" 2015, nr 6. 
nymi postaci i narratorów, futurologia dąży do depersonalizacji; konsekwencją wyobrażeń futurologicznych powinny być społeczne działania, czytelników science fiction jako fikcji to wezwanie nie obowiązuje. A jednak, obie dziedziny znów się spotykają, tym razem za sprawą futurologii, w ostatniej fazie rozwoju futures studies: przyszłość jest otwarta, futuryści studiują jej „obrazy” i wyobrażenia oraz opracowują własne jej warianty, które stają się areną gry o wartości, w efekcie bowiem zmierzają do niebezpiecznego zbliżenia przewidywania, kreacji i kontroli ${ }^{15}$. Generalnie, można zgodzić się $\mathrm{z}$ twierdzeniem, że science fiction stanowi poszerzenie możliwości futurologii ${ }^{16}$, nie tylko dlatego, że nie jest skrępowana zależnościami finansowymi i politycznymi, lecz przede wszystkim dlatego, że oferuje nieporównywanie bardziej rozbudowaną modalność światów możliwych, pozwala na uzależnianie różnych odcieni „realności” / realistyczności od jakości i poziomu obserwacji, na manipulacje nieostrą granicą między realnością a fikcjonalnością, wreszcie - angażuje postawę emocjonalną dzięki holistycznej kreacji świata możliwego i perswazyjnemu wciągnięciu czytelnika w jego rekonstrukcję.

Skomplikowane światostwórstwo tak jest prowadzone, by umożliwiało porównywanie świata realnego $\mathrm{z}$ fantastycznym. Retrofuturyzm rozwija konsekwentną linię czasową wywodzącą się z punktu rozgałęzienia (turning point, moment of divergence ${ }^{17}$ ). Spójność odczuwania "teraz" jako sposobu interpretacji "dawniej” i „dziś" 18 pociąga za sobą wysoki stopień konwencjonalizacji retrofuturystycznych utworów, co widać szczególnie właśnie na przykładzie steampunku. Stabilizacja w tym zakresie może rekompensować większe rozchwianie temporalne niż w przypadku utworów realistycznych.

Ponieważ retrofuturyzm posługuje się wizją niezrealizowanej przyszłości, towarzyszyć mu może nostalgia za niespełnionym wariantem, wprost proporcjonalna do stopnia odrzucenia teraźniejszości. Nostalgię z szerszą postawą i stylem retro (dziś w popularniejszym wariancie vintage) łączy Elizabeth E. Guffey ${ }^{19}$. Zainteresowanie spójną misternością konstrukcji fikcyjnej rzeczywistości, która nie tylko posiada równoległy stan teraźniejszy, ale także równoległą historię, począwszy od momentu rozgałęzienia, pobudza czytel-

15 Th. Lombardo, Contemporary Futurist Thought: Science Fiction, Future Studies, and Theories and Visions of the Future in the Last Century, Bloomington 2008, s. 173-178.

16 Tamże, s. 173.

17 R. Vogt, "If the Stranger hadn't been there... But he was!" Causal, Virtualand Evaluative Dimensions of Turning Points in Alternate Histories, Science-Fiction Stories and Multiverse Narratives, w: Turning Points. Concepts and Narratives of Change in Literature and Other Media, red. A. Nünning, K.M. Sicks, Berlin-Boston 2012, s. 107-115.

18 C. Hammond, Time Warped, s. 15.

19 E.E. Guffey, Retro. The Culture of Revival, London 2006. 
niczą fascynację związaną z immersywną strategią odbioru. Światostwórstwo - „zdolność do wyobrażenia sobie przyszłości wiąże się z wyobraźnią przestrzenną" (czasoprzestrzeń) ${ }^{20}$. Retrofuturyzm podejmuje zatem, w ramach swego metafikcjonalnego nastawienia, próbę rozpoznania mechanizmów generowania i interioryzacji światoobrazów, w którym łatwo można dokonywać podstawień poszczególnych elementów rzeczywistości, od technologii po ideologię.

Mentalne operacje poznawcze, doświadczenie zagubienia i proces orientowania się $\mathrm{w}$ fikcyjnej rzeczywistości warto zestawić $\mathrm{z}$ typologią osobowości budowaną na podstawach orientacji temporalnej. Oto "sześć typowych perspektyw postrzegania czasu w świecie zachodnim": przeszła pozytywna, przeszła negatywna, teraźniejszość hedonistyczna, teraźniejszość fatalistyczna, przyszła oraz transcendentalna ${ }^{21}$. Trzeba od razu zauważyć, że wszystkie perspektywy noszą ślady ciążenia przyszłości, czyli zdarzeń, które ,jeszcze nie nadeszły”, a nie tych, które „mogą zajść, jeśli...”. Im bliżej przyszłości, tym bardziej to zjawisko widać w samej kategoryzacji. Przekroczenie progu transcendencji (postawa transcendentalna) nie niesie ze sobą pewnych rozstrzygnięć co do przyszłości człowieka Zachodu, nie mieści się bez reszty w logicznej formule ,jeśli - wówczas", choć wyraźnie współdecyduje o ludzkim zachowaniu i myśleniu. Perspektywy teraźniejsze są z kolei opanowane przez wizję przyszłości; żyjemy tak, by nasz przyszły "prywatny” świat umożliwiał nam realizację lub podtrzymanie naszej „prywatnej" hierarchii wartości. Nad tą hierarchią stopniowo utwierdza się rama ontyczna, gdy próbujemy znaleźć odpowiedzi na pytania: w jakim zakresie decyduję o swoim losie, w jakim zakresie moje czyny decydują o losach innych ludzi?

Wreszcie, perspektywy przeszłe budują te zachowania mentalne, które z punktu widzenia terapeuty kreślą główne rysy osobowościowe. Poszczególne perspektywy mogą dominować w światoobrazach, ale istnieje też ścieżka optymalna - "balanced time perspective", zapewniająca psychiczną równowagę ${ }^{22}$. Dzięki fikcji fantastycznej perspektywy te są ożywiane, zwłaszcza że swoisty determinizm ekstrapolacyjny, czyli zapętlenie relacji między wykreowaną przeszłością, teraźniejszością a przyszłością może być w fikcji ukazywane in statu nascendi. W zakresie „konotacji semantyki czasu” 23

\footnotetext{
20 C. Hammond, Time Warped, s. 220.

21 J. Boyd, Ph. Zimbardo, Paradoks czasu, przeł. A. Cybulko, M. Zieliński, Warszawa 2013.

22 C. Hammond, Time Warped, s. 185.

23 K. Bartoszyński, Czasu konstrukcje w literaturze polskiej XX wieku, w: Słownik literatury polskiej XX wieku, red. A. Brodzka i in., Wrocław 1993.
} 
dokonuje się tak duże splątanie płaszczyzn czasowych, że tworzy się wrażenie uniwersum „blokowego", w którym wydarzenia istnieją bezczasowo, a konkretne płaszczyzny temporalne są wtórne i nie stanowią o prymarnej kategoryzacji zdarzeń ${ }^{24}$. Postawa retrocentryczna pozwala na test synchronizacji, rytm indywidualny („prywatny”) można synchronizować z cywilizacyjnym, co świetnie ujęła Elizabeth E. Guffey w tytule wstępu do swej monografii Retro: the Culture of Revival - Remembering When We Were Modern ${ }^{25}$. Wydaje się, że jest to nostalgiczny akt powrotu do przeszłego doświadczenia jako przeciwieństwa traumy. Powrót do modernizmu przypomina powrót do budującej młodości. Pozostaje on ambiwalentny, nie jest to bowiem powrót do surowego doświadczenia, ale przypominanie wspomnień, utrwalanie schematu doświadczenia, by mogło się ono krzyżować z innymi wspomnieniami, było otwarte na reinterpretacje: "this tendency should not be dismissed as merely a series of reflexive stylistic gestures. Instead, it might be more usefully seen as representing a kind of subversion in which the artistic and cultural vanguard began looking backwards in order to go forwards" 26 . Powrót jest zatem naznaczony „ironicznymi i wywrotowymi instynktami" 27. Inaczej jednak niż w "czystej” postawie retro, postawa retrofuturystyczna gwałtownie zderza czasowe perspektywy obu uniwersów, w pełnych napięcia wychyleniach w przeszłość i przyszłość, wewnątrz "teraz" projektowanego też na przeszłość ${ }^{28}$. Mark Currie w swej monografii fikcyjnego czasu zatytułowanej About Time szczególną uwagą obdarza tezy Jacques'a Derridy z książki Archive Fever, w której francuski filozof demonstruje dynamikę powiązania płaszczyzn czasowych: „The temporal structure of a present lived as it were the object of a future memory". "Gorączka archiwum" zdominowana jest zatem przez przyszłość, ale nie tę, która nadejdzie, lecz tę zakładaną ${ }^{29}$. Podobnie pisał wcześniej Frank Kermode o wyobraźni apokaliptycznej ${ }^{30}$.

\footnotetext{
24 Uniwersa przypominają bazy danych; czasowość jest wówczas zaledwie cechą obiektu.

25 E.E. Guffey, Retro. The Culture of Revival, s. 7.

26 Tamże, s. 8.

27 Tamże, s. 14, 21.

28 Efektem ubocznym amnezji jest niezdolność do wyobrażenia sobie przyszłości - C. Hammond, Time Warped, s. 213.

29 ,"[A]rchive fever is above all a future orientation or a mode of anticipation, which structures the present" [M. Currie, About Time: Narrative, Fiction and the Philosophy of Time, Edinburgh 2007, s. 11].

30 F. Kermode, The Sense of an Ending: Studies in the Theory of Fiction with a New Epilogue, Oxford 2000 (pierwsze wydanie w 1967 r.).
} 
Immersywna taktyka utworów retrofuturystycznych podszyta jest zatem emocjami, zderzaniem nadziei i lęków, futurologii i fantastyki, wahaniem między postawą utopijną a dystopijną, między traumą a doświadczeniem budującym. Science fiction, w tym wariancie, dąży do "allotopizacji” każdej chwili doświadczenia, ale jest to ruch analogiczny do utopijnego - nieustanna praca uchronii. Staje się ona narzędziem kontrolowanej, ale niepokojącej desynchronizacji pozornie jednokierunkowej linii czasowej.

\section{Nostalgia in Retrofuturism}

\section{Summary}

Science fiction novels are chronologically located where multiple time references intersect. Future dominates the semantics of the novel whereas past reference organizes the grammar of the narrative. Nostalgic retrofuturism explicitly demonstrates the tensions between various time modes, and as a result it shows a vision of "the future which has never happened".

Keywords: retrofuturism, science fiction, steampunk, fictional time 